Check for updates

Cite this: RSC Adv., 2018, 8, 36280

\title{
XPS and Raman study of the active-sites on molybdenum disulfide nanopetals for photocatalytic removal of rhodamine B and doxycycline hydrochlride $\uparrow$
}

\author{
Xuefeng $\mathrm{Ai}^{\text {ab }}$ Hougang Fan, ${ }^{\text {*abc }}$ Yijun Wang, ${ }^{\text {b }}$ Yumeng Guo, ${ }^{\mathrm{b}}$ Xiaoyan Liu, ${ }^{\text {ab }}$ \\ Lili Yang, ${ }^{\text {abc }}$ Huilian Liu ${ }^{\text {abc }}$ and Jinghai Yang (D) *abc
}

Molybdenum disulfide $\left(\mathrm{MoS}_{2}\right)$ nanopetals were successfully synthesized by hydrothermal method (sample without sintering) and then sintered at different temperature (sintered samples). The products were characterized by X-ray powder diffraction (XRD), scanning electron microscopy (SEM), transmission electron microscopy (TEM), nitrogen $\left(\mathrm{N}_{2}\right)$ adsorption analyses for Brunauer-Emmett-Teller (BET) specific surface area measurements, X-ray photoelectron spectrum (XPS) and Raman spectrum. XRD pattern indicated that the samples can be indexed to hexagonal phase $2 \mathrm{H}-\mathrm{MOS}_{2}$. SEM and TEM images showed that the sintered $\mathrm{MoS}_{2}$ nanopetals had sizes ranging from 150 to $300 \mathrm{~nm}$ with almost the same morphology. The pore structure and surface area were nearly the same for the three sintered $\mathrm{MoS}_{2}$ nanopetals. Interestingly, XPS and Raman spectra implied that there was a few 1T-phase in the $\mathrm{MoS}_{2}$ nanopetals which enhanced the photocatalytic performance greatly when sintered at low temperature.

Received 27th September 2018 Accepted 19th October 2018

DOI: $10.1039 / c 8 r a 08027 e$

rsc.li/rsc-advances and enhance their photocatalytic performance. Here we have prepared petal-spherical like $\mathrm{MoS}_{2}$ photocatalysts by hydrothermal method and some of the samples were then sintered at $573 \mathrm{~K}, 673 \mathrm{~K}$ and $773 \mathrm{~K}$ for $4 \mathrm{~h}$, respectively. We studied four samples, the sample without sintering (as-prepared), and the samples sintered at $573 \mathrm{~K}, 673 \mathrm{~K}$ and $773 \mathrm{~K}$, respectively. We found that the photocatalytic removal of Rhodamine $\mathrm{B}$ (RhB) and doxycycline hydrochloride (DCHC) in the sintered samples were better than that in the as-prepared sample. The sample sintered at $573 \mathrm{~K}$ could remove $99 \%$ of RhB and DCHC in $60 \mathrm{~min}$. However, after sintered at higher temperature of $673 \mathrm{~K}$ and $773 \mathrm{~K}$ their photocatalytic performance decreased to some extent. We studied their XRD, SEM, TEM, BET specific surface area, XPS and Raman data to find the effect of the active-sites in the $\mathrm{MoS}_{2}$ nanopetals.

\section{Results and discussion}

Structure and morphology of $\mathrm{MoS}_{2}$ nanopetals

The XRD patterns of the four samples were shown in Fig. 1. The peaks located at around $13^{\circ}, 34^{\circ}, 39^{\circ}, 50^{\circ}$ and $58^{\circ}$ corresponded to the (002), (100), (103), (105) and (110) reflections, respectively, which indicated that all the samples were $2 \mathrm{H}-\mathrm{MoS}_{2}$ (JCPDS 371492 $)^{\mathbf{1 0 , 1 1}}$ except for the as-prepared sample. For the as-prepared sample, there was an unknown peak located at about $24^{\circ}$ which might be sort of organic substance. After sintered, the impurity disappeared. With the sintered temperature increasing, one could not observe obvious differences between the three 


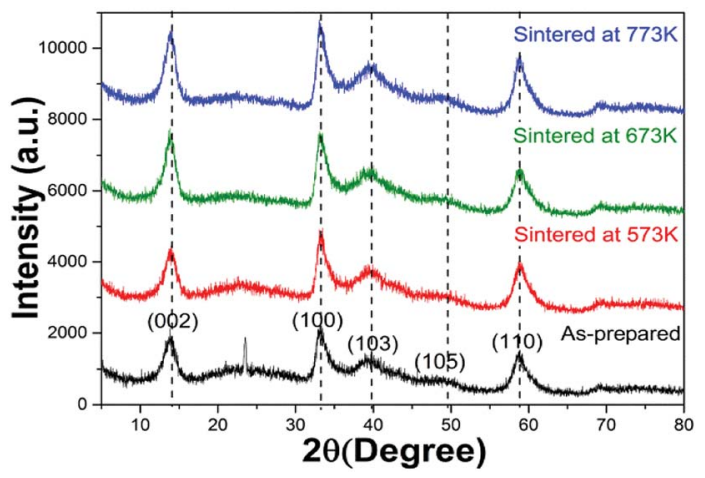

Fig. 1 XRD patterns of the four $\mathrm{MoS}_{2}$ samples.

samples. There was no sign of the existence of $1 \mathrm{~T}-\mathrm{MoS}_{2}$ since most of XRD peaks of 1T-MoS ${ }_{2}$ overlapped with $2 \mathrm{H}-\mathrm{MoS}_{2} \cdot{ }^{12}$

Fig. 2(A, C and E) showed the SEM images of the three sintered samples. They all had the similar shape of petal-spherical like and the diameter of the petals ranged from 150 to $300 \mathrm{~nm}$. No obvious difference could be seen between them. Fig. 2(B, D and F) showed the corresponding TEM images. There was no apparent difference between the three samples either. Both the SEM and TEM images showed the sintered samples had
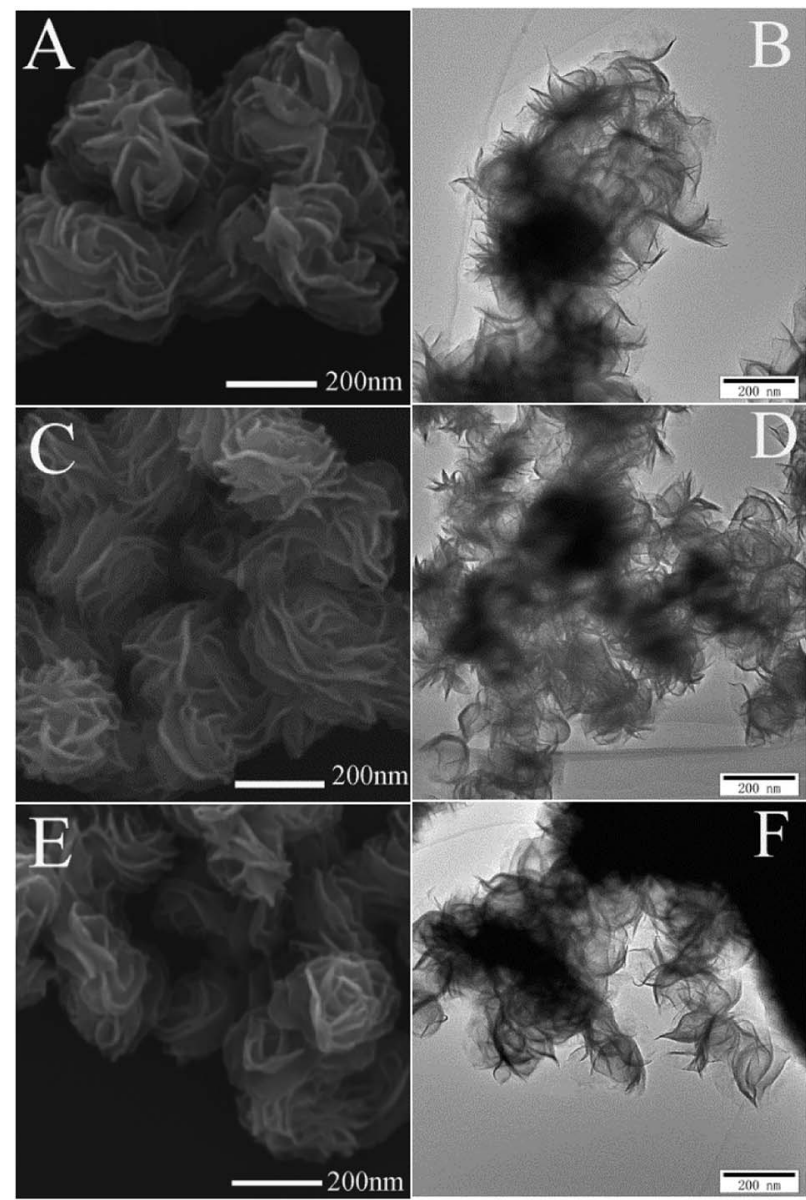

Fig. 2 SEM and TEM images of $M_{2} S_{2}$ nanopetals sintered at (A and $B$ ) $573 \mathrm{~K},(\mathrm{C}$ and $\mathrm{D}) 673 \mathrm{~K}$ and ( $\mathrm{E}$ and $\mathrm{F}) 773 \mathrm{~K}$. indistinguishable morphology and the exposed petal edges of them varied little. Thus from XRD, SEM and TEM results, no distinguishable difference could be observed, which implied that the photocatalytic performance of the three samples sintered at different temperature would be similar.

\section{Photocatalytic removal of RhB and DCHC}

Fig. 3 showed the photocatalytic degradation of RhB by the four $\mathrm{MoS}_{2}$ nanopetals. It can be seen that after $30 \mathrm{~min}$ in dark, about $38 \%$ RhB were adsorbed by the as-prepared sample. Nearly $97 \%$, $85 \%$ and $65 \% \mathrm{RhB}$ were adsorbed by the sample sintered at 573 $\mathrm{K}, 673 \mathrm{~K}$ and $773 \mathrm{~K}$, respectively. Since the as-prepared sample had a few organic impurities demonstrated in the above XRD section, the impurities would occupy some active-sites in the asprepared sample, which weakened its ability to adsorb RhB. After sintered at different temperature, the other three samples all showed much better adsorption ability because the impurities would be removed after sintered. Under visible light, the final photocatalytic efficiency were $77 \%, 99 \%, 97 \%$ and $70 \%$ for the above four samples in $60 \mathrm{~min}$.

Fig. 4 showed the photocatalytic removal of DCHC by the four samples, which had similar phenomenon to that of photocatalytic of RhB demonstrated above. For the as-prepared sample, the whole process was nearly linear. While for the

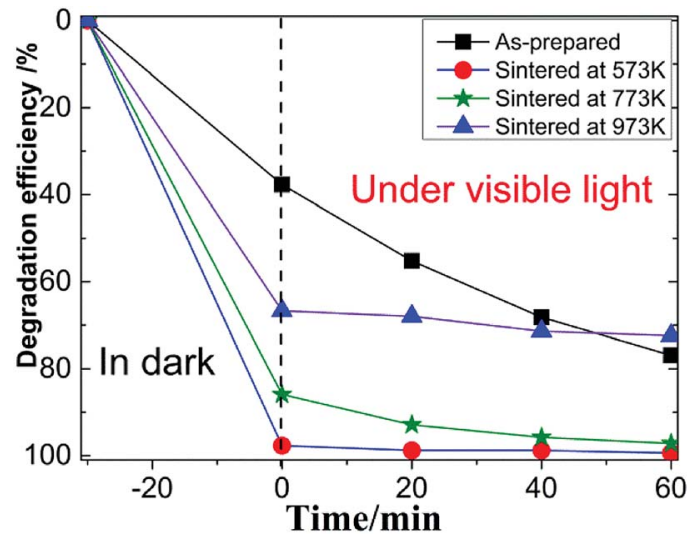

Fig. 3 Photocatalytic degradation of RhB.

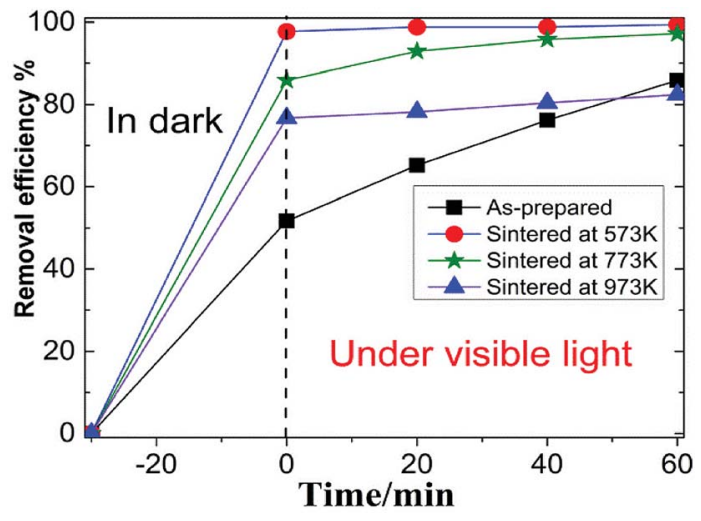

Fig. 4 Photocatalytic removal of DCHC. 
three sintered samples, the whole process would be divided into two types, excellent adsorption part in dark and ordinary photocatalytic degradation process under visible light. We focused our following research on the characteristics of the three sintered samples since they possessed similar process. ${ }^{23,24}$ The recycle performance of the sintered samples was tested and listed in Fig. S1 and S2. $\dagger$ After three cycles, the removal efficiency decreased about $30 \%$. The decreasing of the adsorption ability of the three sintered samples implied that the specific surface area or the number of the active-sites in the three samples varied dramatically.

\section{Pore structure and surface area determination}

In order to study the effect of the specific surface area of the sintered $\mathrm{MoS}_{2}$ nanopetals, we had performed the $\mathrm{N}_{2}$ adsorption measurement on the above three samples. The BET isotherm data of the three sintered $\mathrm{MoS}_{2}$ samples were plotted in Fig. 5 . According to the International Union of Pure and Applied Chemistry (IUPAC) classification, all the samples exhibited similar reversible type III isotherms, ${ }^{25,26}$ which demonstrated that the adsorption in the $\mathrm{MoS}_{2}$ nanopetals belonged to multilayer adsorption coincided with the morphology of the petal-spherical shown in the SEM images. The corresponding pore size distribution histograms of the three samples also showed almost the same pattern, which were plotted in Fig. S3. $\dagger$ The data summarized in Table $\mathrm{S} 1 \uparrow$ indicated that the BET specific surface area of the three sintered $\mathrm{MoS}_{2}$ samples were all around $140.00 \mathrm{~m}^{2} \mathrm{~g}^{-1}$. The similar pore size distribution and nearly the same specific surface area inferred that all the sintered samples should have similar adsorption ability without large difference. However it was contrary to the truth shown in Fig. 3 and 4 . Thus, the effect of the active-sites in the sintered $\mathrm{MoS}_{2}$ nanopetals might be crucial.

\section{Structural composition analysis of $\mathrm{MoS}_{2}$ nanopetals}

To find the variation of the active-sites in the $\mathrm{MoS}_{2}$ nanopetals with sintered temperature increasing, we performed the XPS and Raman measurements and explored the data in depth. Fig. 6 showed the Raman spectra of the above three sintered

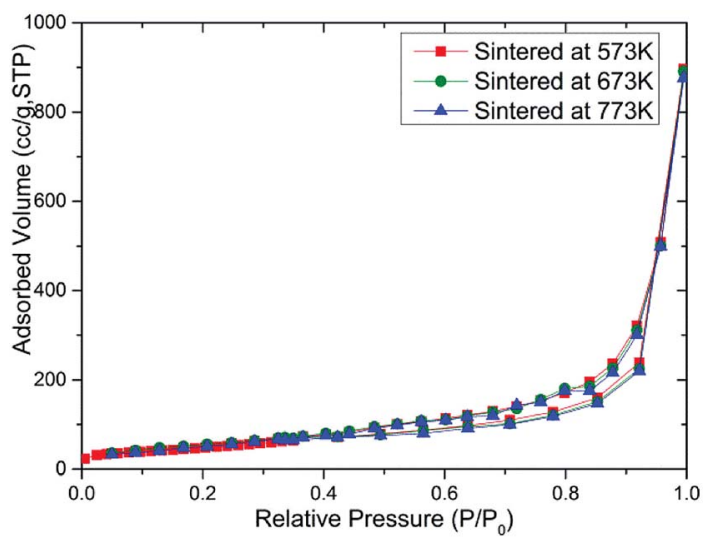

Fig. 5 BET isotherm of the sintered $\mathrm{MoS}_{2}$ samples.

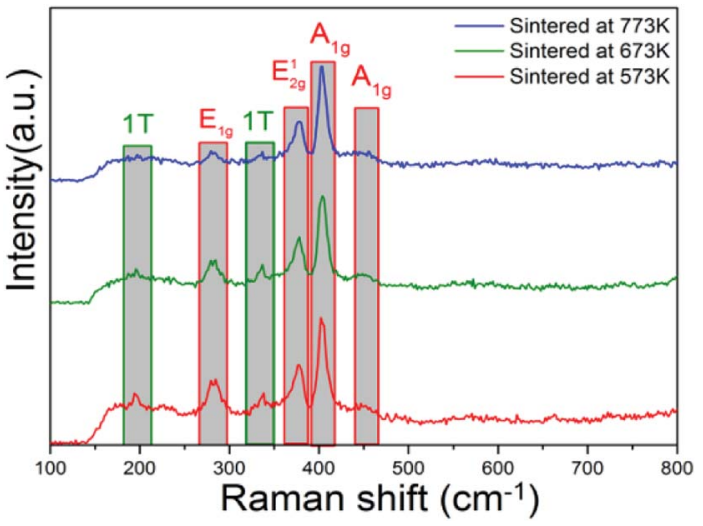

Fig. 6 Raman spectra of the sintered $\mathrm{MoS}_{2}$ samples.

samples. The peaks located at around $282 \mathrm{~cm}^{-1}$ and $382 \mathrm{~cm}^{-1}$ corresponded to the $\mathrm{E}_{1 \mathrm{~g}}$ and $\mathrm{E}_{2 \mathrm{~g}}^{1}$ vibration modes of $2 \mathrm{H}-\mathrm{MoS}_{2}$ and the peaks at about $403 \mathrm{~cm}^{-1}$ and $454 \mathrm{~cm}^{-1}$ corresponded to the $\mathrm{A}_{1 \mathrm{~g}}$ vibration modes of $2 \mathrm{H}-\mathrm{MoS}_{2} \cdot{ }^{12,13,27,28}$ Two small peaks at $197 \mathrm{~cm}^{-1}$ and $337 \mathrm{~cm}^{-1}$ corresponded to the phonon mode in $1 \mathrm{~T}-\mathrm{MoS}_{2} \cdot{ }^{12,13,27,28}$ It could be observed that the intensity of the two $1 \mathrm{~T}$ peaks decreased dramatically with the sintered temperature increasing. We calculated the ratios of the integral area of $1 \mathrm{~T}$ peak at $197 \mathrm{~cm}^{-1}$ to $2 \mathrm{H}-\mathrm{A}_{1 \mathrm{~g}}$ peak at $403 \mathrm{~cm}^{-1}$ and $1 \mathrm{~T}$ peak at $337 \mathrm{~cm}^{-1}$ to $2 \mathrm{H}-\mathrm{A}_{1 \mathrm{~g}}$ peak at $403 \mathrm{~cm}^{-1}$, respectively, the results were listed in Table 1 . We assume that the active-sites played a crucial role for the photocatalytic removal of $\mathrm{RhB}$ and DCHC. Since the $1 \mathrm{~T}-\mathrm{MoS}_{2}$ possessed more active-sites than that in $2 \mathrm{H}-\mathrm{MoS}_{2}$, the more $1 \mathrm{~T}-\mathrm{MoS}_{2}$, the more the active-sites in the nanopetals. With the sintered temperature increasing, more and more $1 \mathrm{~T}-\mathrm{MoS}_{2}$ transformed to $2 \mathrm{H}-\mathrm{MoS}_{2}$, which resulted in the decreasing of the number of the active-sites in the sintered $\mathrm{MoS}_{2}$ nanopetals. Eventually, the photocatalytic removal of RhB and DCHC also decreased dramatically.

In order to confirm the above assumption, we carried out the XPS measurement of the Mo-3d and S-2p of the three sintered $\mathrm{MoS}_{2}$ samples and plotted the spectra in Fig. 7. It can be observed that the binding energy shifted to lower value for about $0.3 \mathrm{eV}$ with the sintered temperature increasing, no other distinguishable difference could be observed. We deconvoluted the XPS data to analyse the phase contents of $1 \mathrm{~T}-\mathrm{MoS}_{2}$ and $2 \mathrm{H}$ $\mathrm{MoS}_{2}$. The Mo-3d and S-2p peaks were deconvoluted to show the $1 \mathrm{~T}-\mathrm{MoS}_{2}$ and $2 \mathrm{H}-\mathrm{MoS}_{2}$ contributions which were shown in Fig. S4. $\dagger$ Both the peaks of Mo-3d and the S-2p regions were shifted to lower energy of about $0.3 \mathrm{eV}$. The Mo-3d spectrum consisted of peaks at around 229.0 and $232.3 \mathrm{eV}$, which

Table 1 The ratios of integral area of $1 T$ peak to $2 \mathrm{H}-\mathrm{A}_{1 \mathrm{~g}}$ peak in Raman spectra of the sintered $\mathrm{MoS}_{2}$ samples

\begin{tabular}{lll}
\hline & $1 \mathrm{~T}\left(197 \mathrm{~cm}^{-1}\right) /$ & $1 \mathrm{~T}\left(337 \mathrm{~cm}^{-1}\right) /$ \\
Sample & $\mathrm{A}_{1 \mathrm{~g}}\left(403 \mathrm{~cm}^{-1}\right)$ & $\mathrm{A}_{1 \mathrm{~g}}\left(403 \mathrm{~cm}^{-1}\right)$ \\
\hline Sintered at $573 \mathrm{~K}$ & 0.117 & 0.124 \\
Sintered at $673 \mathrm{~K}$ & 0.064 & 0.123 \\
Sintered at 773K & 0.001 & 0.003
\end{tabular}




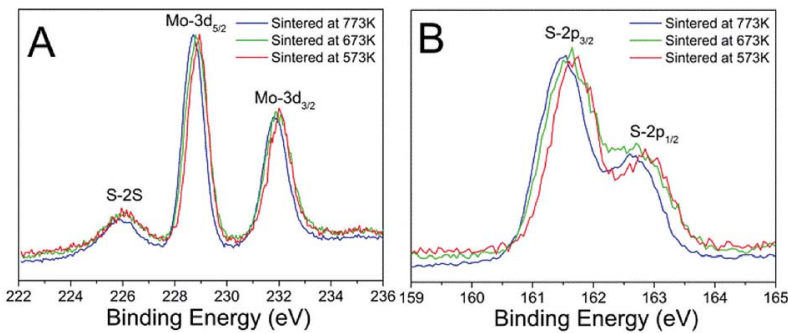

Fig. 7 XPS spectra of the $\mathrm{MoS}_{2}$ samples (A) Mo-3d; (B) S-2p.

Table 2 The contents of $1 \mathrm{~T}-\mathrm{MoS}_{2}$ in the sintered $\mathrm{MoS}_{2}$ samples

\begin{tabular}{lrr}
\hline Sample & $\mathrm{Mo}^{4+}$-XPS & $\mathrm{S}^{2+}-\mathrm{XPS}$ \\
\hline Sintered at 573K & $12.19 \%$ & $11.40 \%$ \\
Sintered at 673K & $9.70 \%$ & $9.21 \%$ \\
Sintered at 773K & $3.61 \%$ & $3.70 \%$ \\
\hline
\end{tabular}

correspond to $\mathrm{Mo}^{4+}-3 \mathrm{~d}_{5 / 2}$ and $\mathrm{Mo}^{4+}-3 \mathrm{~d}_{3 / 2}$ components of the $2 \mathrm{H}-$ phase, respectively, ${ }^{\mathbf{1 3 , 2 3 , 2 4}}$ and peaks at around 228.1 and $231.4 \mathrm{eV}$ correspond to $\mathrm{Mo}^{4+}-3 \mathrm{~d}_{5 / 2}$ and $\mathrm{Mo}^{4+}-3 \mathrm{~d}_{3 / 2}$ components of the 1T-phase..$^{13,23,24}$ The ratios of $1 \mathrm{~T}-\mathrm{MoS}_{2}$ in the three $\mathrm{MoS}_{2}$ samples were listed in Table 2 .

It was clear that the content of $1 \mathrm{~T}-\mathrm{MoS}_{2}$ decreased from $12.19 \%$ to $4.60 \%$ with the sintered temperature increased from $573 \mathrm{~K}$ to $773 \mathrm{~K}$, which coincided with the analysis of the above Raman spectra that $1 \mathrm{~T}-\mathrm{MoS}_{2}$ was unstable and reduced notably when sintered at high temperature..$^{12,13,27,28}$ The analysis of the S$2 \mathrm{p}$ peaks also showed the similar results that the content of $1 \mathrm{~T}$ $\mathrm{MoS}_{2}$ decreased from $11.40 \%$ to $3.70 \%$.

\section{The crucial role of active-sites}

To demonstrate clearly the assumption that the active-sites in the 1T-phase played a crucial role for the photocatalytic removal of RhB and DCHC, we plotted Fig. 8 to show the active-sites distribution in the nanopetals. It could be observed that the petals stacked and formed the shape of rose-like and there were two kinds of active-sites on the petals, one located on the blue edges of the petals and the other located on the red surface of the petals. In the $2 \mathrm{H}-\mathrm{MoS}_{2}$ there was only one kind of activesites located on the blue edges of petals which corresponded to the edges of the S-Mo-S layers. ${ }^{12,13}$ While In the $1 \mathrm{~T}-\mathrm{MoS}_{2}$, both the blue edges and the red surface of the petals would be the active-sites, ${ }^{12,13}$ which corresponded to the surface of the $S$ layers in $\operatorname{MoS}_{2} \cdot{ }^{12,13}$ So for the three sintered samples, the activesites located on the edges of the petals had an overall majority which would absorb RhB and DCHC as demonstrated by the blue arrows in Fig. 8. The active-sites located on the red surface of the petals would only work when the petals contained of 1T$\mathrm{MoS}_{2}$. For the $\mathrm{MoS}_{2}$ nanopetals sintered at $573 \mathrm{~K}$, besides the active-sites located on the blue edges of the petals, there would be a small amount of $1 \mathrm{~T}-\mathrm{MoS}_{2}$ nanopetals with active-sites located on tiny amounts of red surface of the petals, which made this sample have the best photocatalytic performance

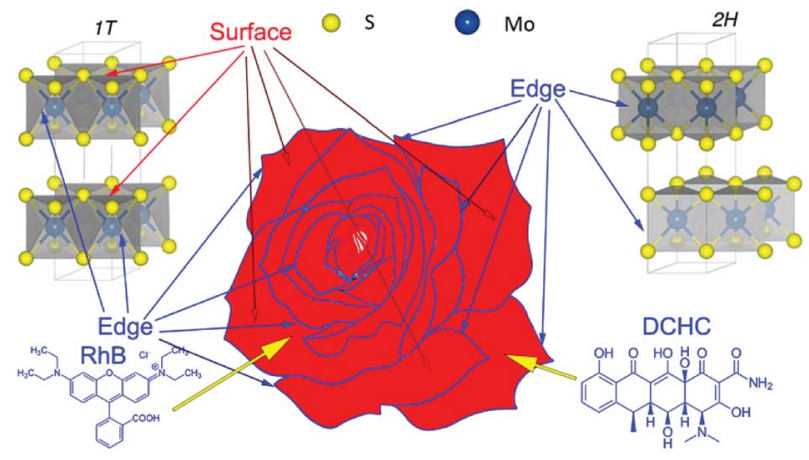

Fig. 8 Schematic diagram of photocatalytic removal of RhB and $\mathrm{DCHC}$ on $\mathrm{MoS}_{2}$ nanopetals.

among the three samples. With the sintered temperature increased the $1 \mathrm{~T}-\mathrm{MoS}_{2}$ would transform to $2 \mathrm{H}-\mathrm{MoS}_{2}$, which resulted in the content of the $1 \mathrm{~T}-\mathrm{MoS}_{2}$ decreased and the $2 \mathrm{H}$ $\mathrm{MoS}_{2}$ increased. Although the number of petals and the activesites located on the edges of the petals remained almost unchanged, the active-sites located on the surface of the 1T$\mathrm{MoS}_{2}$ nanopetals decreased substantially, which resulted in the decrease of the photocatalytic performance for removal of RhB and DCHC. After absorbed by the active-sites on the petals, when under visible light, RhB and DCHC would be photodegraded by the superoxide radical and hydroxyl radical generated by the photogenerated electrons and holes, respectively. ${ }^{\mathbf{1 3 , 2 9}}$

\section{Experimental}

\section{Synthetic procedures}

The chemicals used in this paper were of analytic purity and used without further purification. According to the synthetic methods in the relevant ref. 21, 22, 30 and $31,250 \mathrm{mg}$ of $\mathrm{Na}_{2}$ $\mathrm{MoO}_{4} \cdot 2 \mathrm{H}_{2} \mathrm{O}$ and $200 \mathrm{mg}$ of $\mathrm{CH}_{3} \mathrm{CSNH}_{2}$ were dissolved in $60 \mathrm{~mL}$ of distilled water. The resulted solution was transferred into a $100 \mathrm{~mL}$ Teflon-lined stainless autoclave and sealed tightly, which was kept at $473 \mathrm{~K}$ for $16 \mathrm{~h}$. Then the autoclave was allowed to cool to room temperature naturally. The resulting products were filtered off, washed with absolute ethanol and distilled water for three times, and dried in vacuum at $333 \mathrm{~K}$ for $12 \mathrm{~h}$ to obtain the as-prepared $\mathrm{MoS}_{2}$. Then, some of the asprepared $\mathrm{MoS}_{2}$ were calcined in a muffle furnace under an atmosphere of argon gas. The calcination temperatures were $573 \mathrm{~K}, 673 \mathrm{~K}$ and $773 \mathrm{~K}$, respectively. The holding time is $4 \mathrm{~h}$ and the heating rate was $5 \mathrm{~K} \mathrm{~min}^{-1}$.

\section{Characterization}

The crystalline structure of samples was determined using X-ray diffraction (XRD MAC Science, MXP18, Japan). The morphology of the as-synthesized samples was characterized by field emission scanning electron microscopy (FESEM, JEOL JEM-2010HR) and transition electron microscope (TEM, JEOL JEM-2010HR). N2 adsorption isotherms were measured using an AUTOSORB-IQ (Quantachrome Instruments, USA). Raman spectra were measured on a Renishaw Raman confocal 
microscopy spectrometer (model 2000, Renishaw, London, UK). The X-ray photoelectron spectroscopy (XPS) was performed using an $\mathrm{Al} \mathrm{K}$ monochromatized source (Thermo Fisher Scientific, Waltham, MA, USA) to acquire elemental information. The laser power was $40 \mathrm{~mW}$, and the excitation wavelength was $514.5 \mathrm{~nm}$. A tube furnace (OTF-1200X, Hefeikejing, Hefei, China) was used for the annealing. The heating rate was 5 $\mathrm{K}_{\min ^{-1}}$.

\section{Photocatalytic activity test}

The photocatalytic performance of the $\mathrm{MoS}_{2}$ nanopetals was evaluated by the photocatalytic removal of $\mathrm{RhB}$ and DCHC aqueous solution. In the experiment, $50 \mathrm{mg}$ of $\mathrm{MoS}_{2}$ nanopetals was dispersed in $50.0 \mathrm{~mL}$ of $\mathrm{RhB}$ and DCHC solution (10 $\mathrm{mg} \mathrm{L}^{-1}$ ) in a $100 \mathrm{~mL}$ beaker, respectively. A $350 \mathrm{~W}$ Xe lamp equipped with a $420 \mathrm{~nm}$ cut-off filter was used as a light source, and there was a cooling device to eliminate thermal effect. The average light energy density was estimated to be $68 \mathrm{~mW} \mathrm{~cm}{ }^{-2}$. The distance between the beaker containing the reaction mixture and the light source was fixed at $16 \mathrm{~cm}$. First, the reaction mixture was mechanically stirred for $30 \mathrm{~min}$ in dark to ensure the adsorption/desorption equilibrium of the RhB and DCHC on the surface of the photocatalysts, respectively. The reaction solutions were sampled at 20 min illumination intervals, and the corresponding UV-vis spectra (measured in the range of $300-800 \mathrm{~nm}$ ) were recorded to monitor the progress of the removal of RhB and DCHC by an UV-vis spectrophotometer. To investigate the recycle performance, the sintered samples were reused three times for the photocatalytic degradation of RhB and DCHC under the same condition.

\section{Conclusions}

The $\mathrm{MoS}_{2}$ nanopetals sintered at $573 \mathrm{~K}, 673 \mathrm{~K}$ and $773 \mathrm{~K}$ showed decreasing photocatalytic removal of RhB from $99 \%$ to $97 \%$ then $70 \%$ and removal of DCHC from $99 \%$ to $97 \%$ then $80 \%$. Through analysing the XPS and Raman data, we found that it was the decreasing content of $1 \mathrm{~T}-\mathrm{MoS}_{2}$ from $12.19 \%$ to $9.70 \%$ then $3.7 \%$ which results in the decreasing of the active-sites and the adsorption ability dramatically.

\section{Conflicts of interest}

There are no conflicts to declare.

\section{Acknowledgements}

This research was funded by National Key Research and Development Program of China (Grant No. 2017YFF0108600, 2017YFF0108607), National Natural Science Foundation of China (Grant No. 61775081, 61475063, 61705079, 61605059, 61505067), Program for the development of Science and Technology of Jilin province (Item No. 20180519016JH, 20180520182JH, 20180414008GH), the Thirteenth Five-Year Program for Science and Technology of Education Department of Jilin Province (Item No. JJKH20180771KJ,
JJKH20180780KJ) and the Graduate Innovation Research Fund at the Jilin Normal University (No. 201628).

\section{References}

1 G. Zhang, H. Liu, J. Qua and J. Li, Energy Environ. Sci., 2016, 9, 1190-1209.

2 Y. Okamoto, K. Tamura and T. Kubot, Chem. Commun., 2010, 46, 2748-2750.

3 I. Nabouls, C. F. L. Aponte, B. Lebeau, S. Brunet, L. Michelin, M. Bonne and J. L. Blin, Chem. Commun., 2017, 53, 27172720.

4 J. Y. Oh, J. H. Lee, S. W. Han, S. S. Chae, E. J. Bae, Y. H. Kang, W. J. Choi, S. Y. Cho, J.-O. Lee, H. K. Baik and T. I. Lee, Energy Environ. Sci., 2016, 9, 1696-1705.

5 X. Huang, C. Tan, Z. Yin and H. Zhang, Adv. Mater., 2014, 26, 2185-2204.

6 J. H. Han, M. Kwak, Y. Kim and J. Cheon, Chem. Rev., 2018, 118, 6151-6188.

7 T. M. Gür, Energy Environ. Sci., 2018, 11, 2696-2767.

8 L. Guo, Z. Yang, K. Marcus, B. L. Z. Li, L. Zhou, X. Wang, Y. Du and Y. Yang, Energy Environ. Sci., 2018, 11, 106-114.

9 H. H. Shin, E. Kang, H. Park, T. Han, C.-H. Lee and D.-K. Lim, J. Mater. Chem. A, 2017, 5, 24965-24971.

10 U. Maitra, U. Gupta, M. De, R. Datta, A. Govindaraj and C. N. R. Rao, Angew. Chem., Int. Ed., 2013, 52, 13057-13061.

11 U. K. Sen and S. Mitra, ACS Appl. Mater. Interfaces, 2013, 5, 1240-1247.

12 Y. Fang, J. Pan, J. He, R. Luo, D. Wang, X. Che, K. Bu, W. Zhao, P. Liu, G. Mu, H. Zhang, T. Lin and F. Huang, Angew. Chem., Int. Ed., 2017, 56, 1-5.

13 S. Bai, L. Wang, X. Chen, J. Du and Y. Xiong, Nano Res., 2014, 8, 175-183.

$14 \mathrm{X}$. Yu, T. Shiraki, S. Yang, B. Ding and N. Nakashima, RSC Adv., 2015, 5, 86558-86563.

15 S. S. Karade, D. P. Dubal and B. R. Sankapal, RSC Adv., 2016, 6, 39159-39165.

16 W. Qiao, S. Yan, X. He, X. Song, Z. Li, X. Zhang, W. Zhong and Y. Du, RSC Adv., 2014, 4, 50981-50987.

17 A. Chaudhari, T. Ghoshal, M. T. Shaw, J. O'Connell, R. A. Kelly, C. Glynn, C. O'Dwyer, J. D. Holmes and M. A. Morris, Adv. Mater. Interfaces, 2016, 6, 1500596.

18 S. Han, C. Yuan, X. Luo, Y. Cao, T. Yu, Y. Yang, Q. Li and S. Ye, RSC Adv., 2015, 5, 68283-68286.

19 W. Mengting, T. Yanase, F. Uehara, S. Watanabe, T. Miura, T. Nagahama and T. Shimada, CrystEngComm, 2017, 19, 3915-3920.

20 S. Yu and W. Zheng, Phys. Chem. Chem. Phys., 2016, 18, 46754683.

21 H. Zhu, M. Du, M. Zhang, M. Zou, T. Yang, Y. Fu and J. Yao, J. Mater. Chem. A, 2014, 2, 7680-7685.

22 D. Lin, Y. Li, P. Zhang, W. Zhang, J. Ding, J. Li, G. Wei and Z. Su, RSC Adv., 2016, 6, 52739-52745.

23 Q. Liu, Y. Tian and H. Ai, RSC Adv., 2016, 6, 20971-20978. 24 Z. Zhang, Y. Zhu, H. Asakura, B. Zhang, J. Zhang, M. Zhou, Y. Han, T. Tanaka, A. Wang, T. Zhang and N. Yan, Nat. Commun., 2017, 8, 16100. 
25 M. D. Donohue and G. L. Aranovich, Adv. Colloid Interface Sci., 1998, 76-77, 137-152.

26 M. Kruk and M. Jaroniec, Chem. Mater., 2001, 13, 3169-3183. 27 Y. Guo, D. Sun, B. Ouyang, A. Raja, J. Song, T. F. Heinz and L. E. Brus, Nano Lett., 2015, 15, 5081-5088.

28 X. Fan, P. Xu, D. Zhou, Y. Sun, Y. C. Li, M. A. T. Nguyen, M. Terrones and T. E. Mallouk, Nano Lett., 2015, 15, 59565960 .
29 H. Fan, D. Chen, X. Ai, S. Han, M. Wei, L. Yang, H. Liua and J. Yang, RSC Adv., 2018, 8, 1398-1406.

30 X. Zhang, R. Zhao, Q. Wu, W. Li, C. Shen, L. Ni, H. Yan, G. Diao and M. Chen, ACS Nano, 2017, 11, 8429-8436.

31 T. Xiong, M. Wen, F. Dong, J. Yu, L. Han, B. Lei, Y. Zhang, X. Tang and Z. Zang, Appl. Catal., B, 2016, 199, 87-95. 